\title{
Abiraterone in Metastatic Prostate Cancer without Previous Chemotherapy
}

\author{
Charles J. Ryan, M.D., Matthew R. Smith, M.D., Ph.D., \\ Johann S. de Bono, M.B., Ch.B., Ph.D., Arturo Molina, M.D., \\ Christopher J. Logothetis, M.D., Paul de Souza, M.B., Ph.D., \\ Karim Fizazi, M.D., Ph.D., Paul Mainwaring, M.D., Josep M. Piulats, M.D., Ph.D., \\ Siobhan Ng, M.D., Joan Carles, M.D., Peter F.A. Mulders, M.D., Ph.D., \\ Ethan Basch, M.D., Eric J. Small, M.D., Fred Saad, M.D., Dirk Schrijvers, M.D., Ph.D., \\ Hendrik Van Poppel, M.D., Ph.D., Som D. Mukherjee, M.D., Henrik Suttmann, M.D., \\ Winald R. Gerritsen, M.D., Ph.D., Thomas W. Flaig, M.D., Daniel J. George, M.D., \\ Evan Y. Yu, M.D., Eleni Efstathiou, M.D., Ph.D., Allan Pantuck, M.D., \\ Eric Winquist, M.D., Celestia S. Higano, M.D., Mary-Ellen Taplin, M.D., \\ Youn Park, Ph.D., Thian Kheoh, Ph.D., Thomas Griffin, M.D., Howard I. Scher, M.D., \\ and Dana E. Rathkopf, M.D., for the COU-AA-302 Investigators*
}

A B STRACT

The authors' affiliations are listed in the Appendix. Address reprint requests to Dr. Ryan at the Genitourinary Medical Oncology Program, UCSF Helen Diller Family Comprehensive Cancer Center, 1600 Divisadero St., San Francisco, CA 94115, or at ryanc@medicine.ucsf.edu.

*Additional investigators in the COU-AA302 study are listed in the Supplementary Appendix, available at NEJM.org.

This article was published on December 10, 2012, and updated on January 17, 2013, at NEJM.org.

N EnglJ Med 2013;368:138-48. DOI: 10.1056/NEJMoal209096

Copyright (C) 2012 Massachusetts Medical Society.
BACKGROUND

Abiraterone acetate, an androgen biosynthesis inhibitor, improves overall survival in patients with metastatic castration-resistant prostate cancer after chemotherapy. We evaluated this agent in patients who had not received previous chemotherapy.

METHODS

In this double-blind study, we randomly assigned 1088 patients to receive abiraterone acetate (1000 mg) plus prednisone (5 mg twice daily) or placebo plus prednisone. The coprimary end points were radiographic progression-free survival and overall survival. RESULTS

The study was unblinded after a planned interim analysis that was performed after $43 \%$ of the expected deaths had occurred. The median radiographic progressionfree survival was 16.5 months with abiraterone-prednisone and 8.3 months with prednisone alone (hazard ratio for abiraterone-prednisone vs. prednisone alone, 0.53; $95 \%$ confidence interval [CI], 0.45 to $0.62 ; \mathrm{P}<0.001$ ). Over a median follow-up period of 22.2 months, overall survival was improved with abiraterone-prednisone (median not reached, vs. 27.2 months for prednisone alone; hazard ratio, 0.75; 95\% CI, 0.61 to 0.93 ; $\mathrm{P}=0.01$ ) but did not cross the efficacy boundary. Abiraterone-prednisone showed superiority over prednisone alone with respect to time to initiation of cytotoxic chemotherapy, opiate use for cancer-related pain, prostate-specific antigen progression, and decline in performance status. Grade 3 or 4 mineralocorticoid-related adverse events and abnormalities on liver-function testing were more common with abiraterone-prednisone.

CONCLUSIONS

Abiraterone improved radiographic progression-free survival, showed a trend toward improved overall survival, and significantly delayed clinical decline and initiation of chemotherapy in patients with metastatic castration-resistant prostate cancer. (Funded by Janssen Research and Development, formerly Cougar Biotechnology; ClinicalTrials.gov number, NCT00887198.) 
ETASTATIC CASTRATION-RESISTANT prostate cancer, defined by tumor growth despite a testosterone level of less than 50 ng per deciliter (1.7 nmol per liter), causes approximately 258,400 deaths annually worldwide. ${ }^{1,2}$ Death of patients with this condition, which typically occurs within 24 to 48 months after the onset of castration resistance, is commonly preceded by a sequence of landmark events associated with deterioration of overall health and worsening symptoms (Fig. S1 in the Supplementary Appendix, available with the full text of this article at NEJM.org)..$^{3-7}$

Among the treatment options for patients with metastatic castration-resistant prostate cancer who have not undergone chemotherapy are a variety of second-line hormonal manipulations ${ }^{8}$ that produce responses in many patients; however, none of these options have been shown to delay progression or prolong life. Subsequent to such secondline therapy, a standard approach is docetaxel chemotherapy, which has a survival benefit, ${ }^{4}$ although many patients with metastatic castrationresistant prostate cancer never receive it. ${ }^{9,10} \mathrm{Ow}$ ing to the limited use of chemotherapy in the management of metastatic castration-resistant prostate cancer, there is an unmet need for effective therapy that delays or prevents the landmark events that characterize the morbidity associated with this cancer. ${ }^{2}$ One treatment, sipuleucel-T, an immunotherapy, is associated with a modest survival benefit but without tumor regression, symptom relief, or delay in disease progression. ${ }^{11}$

Abiraterone acetate is a first-in-class inhibitor of cytochrome P-450c17, a critical enzyme in extragonadal and testicular androgen synthesis. ${ }^{12-18}$ Abiraterone plus low-dose prednisone improves survival in patients with metastatic castrationresistant prostate cancer who have already received docetaxel, ${ }^{19}$ and the combination therapy has received regulatory approval for this indication. Phase 1 and 2 studies in patients who have not received chemotherapy, however, have shown a high proportion of durable responses, suggesting that the benefits of abiraterone may be optimal in this patient group..$^{20-22}$ In our randomized, phase 3 study, we evaluated the effects of abiraterone plus prednisone on radiographic progressionfree survival, overall survival, increase in pain, and clinically relevant measures of disease progression in patients with progressive metastatic castration-resistant prostate cancer who had not received chemotherapy and in whom clinically significant cancer-related symptoms had not developed.

\section{METHODS}

\section{STUDY OVERSIGHT AND CONDUCT}

This study was designed by academic and sponsoremployed investigators. The lead academic author initially drafted the manuscript with sponsor input, and all coauthors subsequently provided input and approval. The sponsor provided funding for editorial assistance with an early draft of the manuscript. All authors made the decision to submit the manuscript for publication. The database was held at a third-party contract clinical research organization (CRO), and queries were issued by both the sponsor and the CRO staff. The independent CRO statistician provided the results of analysis to an independent data and safety monitoring committee, whose members were invited by the sponsor. The committee monitored safety at regular intervals and evaluated efficacy and safety at prespecified interim analyses. At the time of unblinding, analyses were performed by statisticians who were employees of the sponsor. The authors assume responsibility for the completeness and integrity of the data and the fidelity of the study to the protocol and statistical analysis plan (available at NEJM.org).

The review boards at all participating institutions approved the study, which was conducted according to the principles of the Declaration of Helsinki, the International Conference on Harmonisation, and the Guidelines for Good Clinical Practice. All patients provided written informed consent.

\section{PATIENTS}

Eligibility criteria were an age of 18 years or older; metastatic, histologically or cytologically confirmed adenocarcinoma of the prostate; prostatespecific antigen (PSA) progression according to Prostate Cancer Clinical Trials Working Group 2 (PCWG2) criteria $^{2}$ or radiographic progression in soft tissue or bone with or without PSA progression; ongoing androgen deprivation with a serum testosterone level of less than $50 \mathrm{ng}$ per deciliter (1.7 nmol per liter); an Eastern Cooperative Oncology Group (ECOG) performance status grade of 0 or 1 (asymptomatic or restricted in strenuous activity but ambulatory, respectively); no symp- 
toms or mild symptoms, as defined according to the Brief Pain Inventory-Short Form (BPI-SF) (scores of 0 to 1 [asymptomatic] or 2 to 3 [mildly symptomatic], respectively); and hematologic and chemical laboratory values that met predefined criteria. Previous therapy with an antiandrogen was required. Patients with visceral metastases or patients who had received previous therapy with ketoconazole lasting more than 7 days were excluded.

\section{STUDY DESIGN AND TREATMENT}

In this multinational, double-blind, placebo-controlled study, patients were randomly assigned in a 1:1 ratio to receive abiraterone acetate plus prednisone or placebo plus prednisone. Patients were stratified according to the baseline ECOG performance status grade ( 0 vs. 1 ). Patients in the abiraterone-prednisone group received abiraterone at a dose of $1 \mathrm{~g}$ (administered as four 250-mg tablets), and patients in the prednisone-alone group received four placebo tablets once daily at least 1 hour before and 2 hours after a meal. All patients received prednisone at a dose of $5 \mathrm{mg}$ orally twice daily. Safety and dosing compliance were evaluated during each study visit, at treatment discontinuation if applicable, and at the end-ofstudy visit.

\section{END POINTS}

The coprimary efficacy end points were radiographic progression-free survival and overall survival, defined as the time from randomization to death from any cause. Radiographic progressionfree survival was determined by an independent radiologist who was unaware of study-group assignments, and dates of death were confirmed. Radiographic progression-free survival was defined as freedom from death from any cause; freedom from progression in soft-tissue lesions as measured with the use of computed tomography (CT) or magnetic resonance imaging (MRI), defined as "progressive disease" according to modified Response Evaluation Criteria in Solid Tumors (RECIST) criteria; or progression on bone scanning according to criteria adapted from the PCWG2 (Table $\mathrm{S} 1$ in the Supplementary Appendix). ${ }^{2}$ Changes in PSA level were not included in the definition of radiographic progression-free survival.

The prespecified secondary end points were times to opiate use for cancer-related pain, to initiation of cytotoxic chemotherapy, to a decline in ECOG performance status, and to PSA progression (on the basis of PCWG2 criteria). ${ }^{2}$ Other end points included radiographic progression-free survival as measured by investigators (rather than a blinded review), PSA response rate ( $\geq 50 \%$ decline in PSA level from baseline), rate of objective response according to RECIST criteria, and health-related quality of life, as measured by means of patients' reports of pain and functional status. An increase in pain was defined as an increase in the baseline pain score at two consecutive visits by $30 \%$ or more, as measured by the average of the pain scores on the BPI-SF (range, 0 to 10 , with higher scores indicating worse average pain), without a decrease in analgesic use. A decline in functional status was defined as a decline of 10 or more points in the Functional Assessment of Cancer Therapy-Prostate (FACT-P) total score at any visit (range, 0 to 156, with higher scores indicating better overall quality of life).

\section{ASSESSMENTS}

Efficacy assessments included sequential radiographic imaging to assess radiographic progression-free survival (CT or MRI and bone scanning) and measurement of PSA levels. ${ }^{2} \mathrm{CT}$ or MRI and bone scanning were performed every 8 weeks during the first 24 weeks and every 12 weeks thereafter. All patients underwent serial monitoring of blood chemical levels, hematologic values, coagulation studies, serum lipids, and kidney function. Cardiac safety was monitored by means of serial electrocardiography. The left ventricular ejection fraction was measured at baseline. Patient-reported outcomes were assessed at baseline and at every visit with the use of the BPISF. FACT-P questionnaires were completed every third visit.

\section{STATISTICAL ANALYSIS}

The overall level of significance for the study was 0.05 , allocated between the coprimary end points of radiographic progression-free survival (0.01) and overall survival (0.04). A single analysis was planned for the coprimary end point of radiographic progression-free survival on the basis of a blinded review by the central radiologist after 378 progression-free events, which would provide a statistical power of $91 \%$ to detect a hazard 
ratio of 0.67 at a two-tailed level of significance of 0.01 . The results of subsequent analyses of this end point based on investigator assessment are also reported. For the coprimary end point of overall survival, 773 events were required to detect a hazard ratio of 0.80 at a two-tailed significance level of 0.04 with a statistical power of $85 \%$.

Three interim analyses were planned for overall survival, with the first analysis planned after the observation of approximately 116 of the required 773 events (15\%) (in conjunction with the independent review of radiographic progressionfree survival), the second analysis planned after 311 events (40\%), and the third analysis planned after 425 events (55\%); a final analysis was planned for after 773 events had occurred (Table S2 in the Supplementary Appendix). The group-sequential design was used for the overall survival end point with the use of the O'Brien-Fleming boundaries as implemented by the Lan-DeMets alpha spending method (Table S3 in the Supplementary Appendix).

We planned to enroll approximately $1000 \mathrm{pa}-$ tients in the study. The primary statistical method of comparison for the time-to-event end points was the stratified log-rank test with stratification according to the baseline ECOG score. The Cox proportional-hazards model was used to estimate the hazard ratio and its associated confidence interval. The Hochberg procedure was used to adjust for multiplicity testing of the secondary efficacy end points. ${ }^{23}$ The strength of association between radiographic progression-free survival and overall survival was evaluated by means of Spearman's correlation coefficient estimated with the use of the Clayton copula. ${ }^{24}$

\section{RESULTS}

\section{PATIENTS AND TREATMENT}

From April 2009 through June 2010, we randomly assigned 1088 patients to receive study treatment: abiraterone plus prednisone in 546 patients and placebo plus prednisone in 542 patients (Fig. S2 in the Supplementary Appendix). The clinical cutoff date for the blinded central radiologic review of radiographic progression-free survival and the first overall survival interim analysis was December 20, 2010 (at which time 13\% of deaths had occurred), and the clinical cutoff date for the second interim analysis of overall survival was De- cember 20, 2011 (at which time 43\% of deaths had occurred). The median follow-up duration for all patients was 22.2 months. Baseline demographic characteristics were well balanced between the two study groups (Table S4 in the Supplementary Appendix).

\section{PRIMARY END POINTS}

\section{Radiographic Progression-free Survival}

On the basis of the blinded central radiologic review, at the time of the first interim analysis, treatment with abiraterone plus prednisone, as compared with placebo plus prednisone, resulted in a 57\% reduction in the risk of radiographic progression or death (median not reached vs. median of 8.3 months; hazard ratio for abiraterone-prednisone vs. prednisone alone, 0.43; $95 \%$ confidence interval [CI], 0.35 to $0.52 ; \mathrm{P}<0.001$ ). At the time of the second interim analysis, the median time to radiographic progression-free survival on the basis of investigator assessment was 16.5 months in the abiraterone-prednisone group and 8.3 months in the prednisone-alone group (hazard ratio, $0.53 ; 95 \% \mathrm{CI}, 0.45$ to $0.62 ; \mathrm{P}<0.001$ ) (Fig. 1A). The treatment effect of abiraterone on radiographic progression-free survival was consistently favorable (all hazard ratios, $<1.0$ ) across all prespecified subgroups (Fig. 1C).

\section{Overall Survival}

The planned interim analysis of overall survival was performed after 333 deaths $(43 \%$ of 773 events) were observed. More deaths were observed in the prednisone-alone group than in the abiraterone-prednisone group (186 of 542 patients [34\%] vs. 147 of 546 patients [27\%]). Median overall survival was not reached for the abiraterone-prednisone group and was $\mathbf{2 7 . 2}$ months (95\% CI, 26.0 to not reached) in the prednisonealone group. There was a $25 \%$ decrease in the risk of death in the abiraterone-prednisone group (hazard ratio, 0.75 ; 95\% CI, 0.61 to $0.93 ; \mathrm{P}=0.01$ ) (Fig. 1B), indicating a strong trend toward improved survival with abiraterone-prednisone; however, the prespecified boundary for significance $(\mathrm{P} \leq 0.001)$ was not reached at the observed number of events. The treatment effect of abiraterone on overall survival was consistently favorable (all hazard ratios, <1.0) across all prespecified subgroups (Fig. 1D). Radiographic progression-free survival was positively correlated with overall 


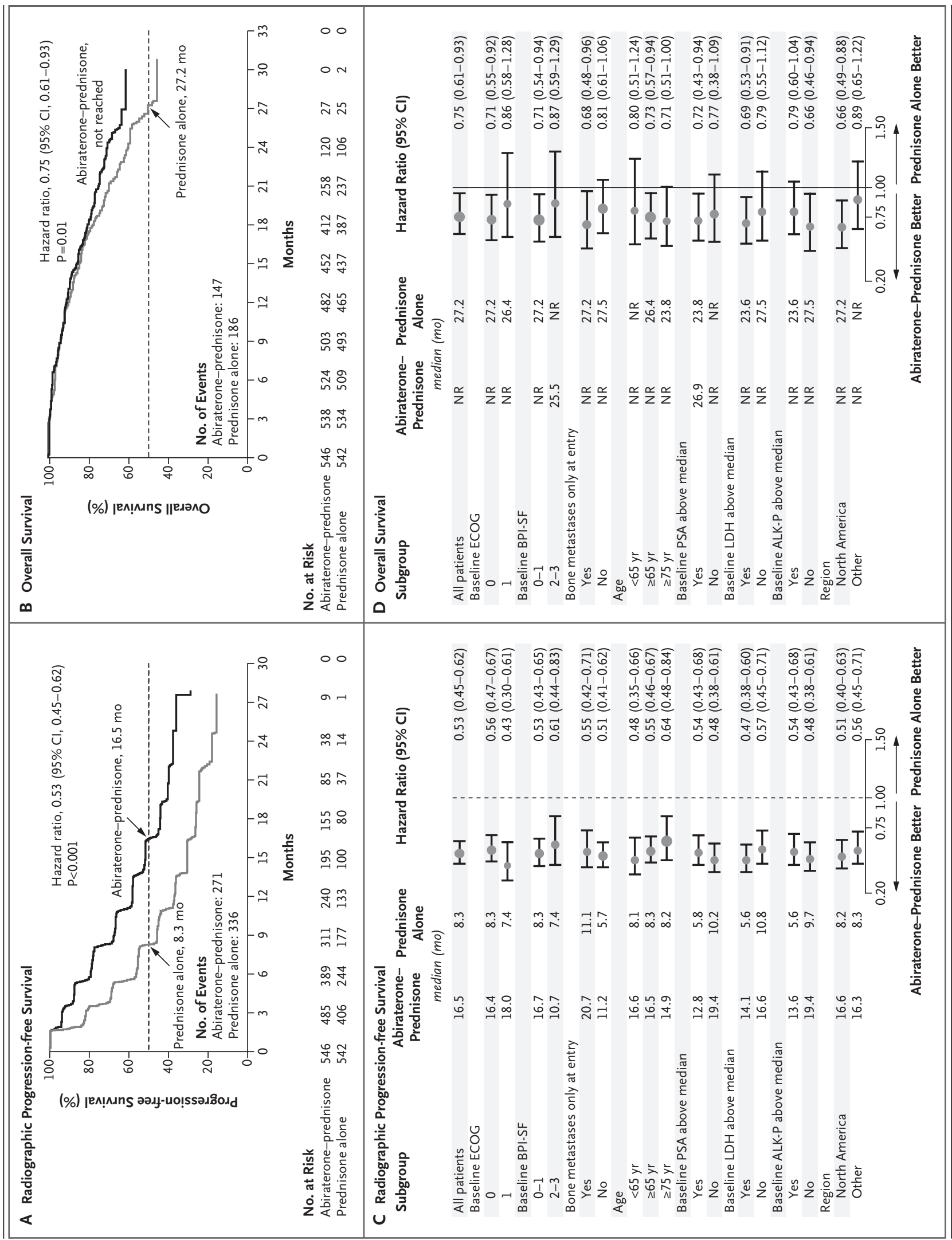


Figure 1 (facing page). Kaplan-Meier Estimates of Radiographic Progression-free Survival, Overall Survival, and Subgroup Analyses at the Second Interim Analysis.

Panels $A$ and $C$ show data for radiographic progressionfree survival on the basis of investigator review, and Panels $B$ and $D$ show data for overall survival. The dashed line in Panels A and B indicates the median. In Panels $C$ and $D$, the size of the circle reflects the number of patients affected. All analyses were performed with the use of a stratified log-rank test according to the baseline score on the Eastern Cooperative Oncology Group (ECOG) scale (a performance status grade of 0 indicates asymptomatic, and 1 restricted in strenuous activity but ambulatory). Scores on the Brief Pain Inventory-Short Form (BPI-SF) range from 0 to 10, with higher scores indicating worse average pain. ALK-P denotes alkaline phosphatase, LDH lactate dehydrogenase, and PSA prostate-specific antigen. survival, with an estimated correlation coefficient of 0.72 .

\section{SECONDARY END POINTS}

Prespecified secondary and exploratory efficacy end points are summarized in Table 1 . Abirateroneprednisone decreased the risk of decline (by $\geq 1$ point) in ECOG performance-status score by $18 \%$, as compared with prednisone alone (time to decline, 12.3 vs. 10.9 months; hazard ratio for decline, $0.82 ; 95 \% \mathrm{CI}, 0.71$ to $0.94 ; \mathrm{P}=0.005$ ) (Fig. 2A). The median time to the initiation of cytotoxic chemotherapy was 25.2 months in the abiraterone-prednisone group and 16.8 months in the prednisone-alone group (hazard ratio, 0.58 ; $95 \%$ CI, 0.49 to 0.69 ; $\mathrm{P}<0.001$ ) (Fig. $2 \mathrm{~B}$ ). A significant delay in the time to opiate use for

\begin{tabular}{|c|c|c|c|c|}
\hline End Point & $\begin{array}{c}\text { Abiraterone- } \\
\text { Prednisone } \\
(\mathrm{N}=546)\end{array}$ & $\begin{array}{c}\text { Prednisone } \\
\text { Alone } \\
(\mathrm{N}=542)\end{array}$ & $\begin{array}{l}\text { Value } \\
(95 \% \mathrm{Cl}) \dagger\end{array}$ & P Value \\
\hline \multicolumn{5}{|l|}{ Secondary end points } \\
\hline Median time to opiate use for cancer-related pain - mo & NR & 23.7 & $0.69(0.57-0.83)$ & $<0.001$ \\
\hline Median time to initiation of cytotoxic chemotherapy - mo & 25.2 & 16.8 & $0.58(0.49-0.69)$ & $<0.001$ \\
\hline $\begin{array}{l}\text { Median time to decline in ECOG performance score by } \\
\quad \geq 1 \text { point }- \text { mo }\end{array}$ & 12.3 & 10.9 & $0.82(0.71-0.94)$ & 0.005 \\
\hline Median time to PSA progression - moł & 11.1 & 5.6 & $0.49(0.42-0.57)$ & $<0.001$ \\
\hline \multicolumn{5}{|l|}{ Exploratory end points $\widehat{\int}$} \\
\hline Median time to increase in pain - mo & 26.7 & 18.4 & $0.82(0.67-1.00)$ & 0.049 \\
\hline $\begin{array}{l}\text { Median time to functional-status decline measured } \\
\text { as FACT-P total score }- \text { mo } \|\end{array}$ & 12.7 & 8.3 & $0.78(0.66-0.92)$ & 0.003 \\
\hline Patients with decline of $\geq 50 \%$ in PSA level — \%** & 62 & 24 & $2.59(2.19-3.05) \dagger$ & $<0.001$ \\
\hline \multicolumn{5}{|l|}{ Patients with a RECIST response - \% } \\
\hline Defined objective response & 36 & 16 & $2.27(1.59-3.25) \dagger$ & $<0.001$ \\
\hline Stable disease & 61 & 69 & & \\
\hline Progressive disease & 2 & 15 & & \\
\hline
\end{tabular}

* Percentages may not sum to 100 because of rounding. $\mathrm{Cl}$ denotes confidence interval, NR not reached, and PSA prostate-specific antigen.

$\dagger$ Values are hazard ratios unless otherwise specified.

+ PSA progression was based on Prostate Cancer Clinical Trials Working Group 2 (PCWG2) criteria. ${ }^{2}$

$\int$ The exploratory analyses are reported with no adjustment for multiplicity.

I Increase in pain is defined as an increase in the baseline pain level by $30 \%$ or more, as measured by the average of the pain scores on the Brief Pain Inventory-Short Form (range, 0 to 10, with higher scores indicating worse average pain) at two consecutive visits, without a decrease in analgesic use.

|| The time to a decline in functional status is defined as the months from randomization to the first date a patient has a decrease of 10 points or more on the Functional Assessment of Cancer Therapy-Prostate (FACT-P) instrument (range, 0 to 156, with higher scores indicating better overall quality of life).

** A decline of $50 \%$ or more in the PSA level was based on modified PCWG2 criteria.

†† Values are relative risks.

Response Evaluation Criteria in Solid Tumors (RECIST) criteria were ascertained in patients with measurable disease at baseline: 220 in the abiraterone-prednisone group and 218 in the prednisone-alone group. 


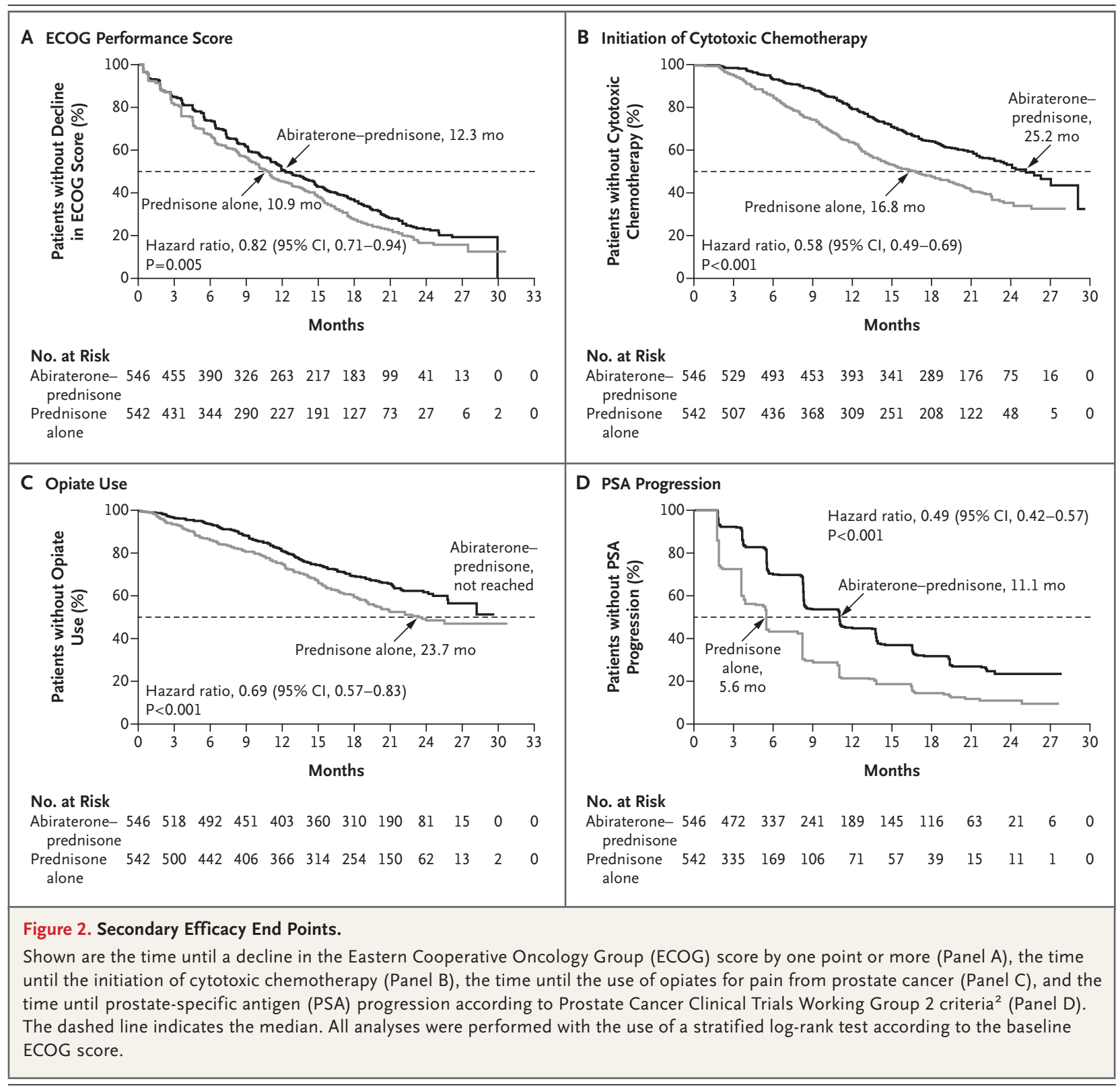

cancer-related pain was observed with abiraterone (not reached vs. 23.7 months; hazard ratio, 0.69; $95 \%$ CI, 0.57 to 0.83 ; P<0.001) (Fig. 2C). The median time to PSA progression was 11.1 months in the abiraterone-prednisone group and 5.6 months in the prednisone-alone group, a 51\% reduction in risk (hazard ratio, 0.49; 95\% CI, 0.42 to 0.57 ; $\mathrm{P}<0.001$ ) (Fig. 2D). On the basis of aggregate efficacy and safety data from the second interim analysis, the data and safety monitoring committee unanimously recommended unblinding the study in February 2012.

\section{OTHER END POINTS}

The median time to increase in pain was 26.7 months among patients receiving abirateroneprednisone and 18.4 months among those receiving prednisone alone (hazard ratio, 0.82; 95\% CI, 0.67 to $1.00 ; \mathrm{P}=0.049$ ) (Table 1 ). The median time to a decline in the FACT-P total score was 12.7 months in the abiraterone-prednisone group and 8.3 months in the prednisone-alone group (hazard ratio, $0.78 ; 95 \% \mathrm{CI}, 0.66$ to $0.92 ; \mathrm{P}=0.003$ ). The rates of PSA response and objective response to therapy were significantly higher in the abir- 
aterone-prednisone group than in the prednisone-alone group (Table 1).

\section{SAFETY}

Adverse events are summarized in Tables 2 and 3. Grade 3 or 4 adverse events were reported in $48 \%$ of patients in the abiraterone-prednisone group and $42 \%$ of patients in the prednisonealone group; serious adverse events were reported in $33 \%$ and $26 \%$ of patients, and adverse events resulting in death were reported in $4 \%$ and $2 \%$ of patients, respectively. Fatigue, arthralgia, and peripheral edema were among the adverse events reported more frequently in the abirateroneprednisone group than in the prednisone-alone group. Grade 3 or 4 adverse events classified as hepatotoxicity, consisting primarily of a reversible elevation in aminotransferase levels, were reported in $8 \%$ of patients in the abirateroneprednisone group and $3 \%$ of patients in the prednisone-alone group. No patient in either study group died from hepatotoxicity-related adverse events.

The frequency of adverse events resulting in treatment discontinuation was similar in the two study groups. A total of $19 \%$ of patients in the abiraterone-prednisone group and $12 \%$ of patients in the prednisone-alone group had adverse events leading to dose modification or interruption of study treatment. In the two study groups, the most frequently occurring adverse events resulting in death were those related to disease progression $(0.6 \%$ of patients in each group). The proportions of patients with grade 3 or 4 serious adverse events were similar in the two groups. Adverse events that were classified as cardiac disorders were reported in 19\% of patients in the abiraterone-prednisone group and $16 \%$ of those in the prednisone-alone group. Mineralocorticoid-related toxic effects were more common in the abiraterone-prednisone group than in the prednisone-alone group, including hypertension ( $22 \%$ vs. $13 \%)$, hypokalemia ( $17 \%$ vs. $13 \%)$, and fluid retention or edema ( $28 \%$ vs. $24 \%$ ), and were mostly grade 1 or 2 adverse events.

\section{DISCUSSION}

In our study involving men with metastatic castration-resistant prostate cancer, abiraterone plus low-dose prednisone resulted in prolonged radio-
Table 2. Adverse Events."

$\begin{array}{lcc} & \begin{array}{c}\text { Abiraterone-Prednisone } \\ \text { (N=542) }\end{array} & \begin{array}{c}\text { Prednisone Alone } \\ \text { (N=540) }\end{array} \\ \text { no. of patients (\%) }\end{array}$

* The most common adverse events leading to death were general disorders, including disease progression, a decline in physical health, and infections including pneumonia and respiratory tract infection.

Table 3. Adverse Events of Special Interest.*

\begin{tabular}{lcccc|}
\hline & \multicolumn{2}{c}{$\begin{array}{c}\text { Abiraterone-Prednisone } \\
\text { Adverse Event }\end{array}$} & \multicolumn{2}{c|}{$\begin{array}{c}\text { Prednisone Alone } \\
\text { (N=542) }\end{array}$} \\
& Grade & Grade & Grade & Grade \\
& $1-4$ & 3 or 4 & $1-4$ & 3 or 4 \\
Fluid retention or edema & $150(28)$ & $4(<1)$ & $127(24)$ & $9(2)$ \\
Hypokalemia & $91(17)$ & $13(2)$ & $68(13)$ & $10(2)$ \\
Hypertension & $118(22)$ & $21(4)$ & $71(13)$ & $16(3)$ \\
Cardiac disordert & $102(19)$ & $31(6)$ & $84(16)$ & $18(3)$ \\
\multicolumn{1}{c}{ Atrial fibrillation } & $22(4)$ & $7(1)$ & $26(5)$ & $5(<1)$ \\
ALT increased & $63(12)$ & $29(5)$ & $27(5)$ & $4(<1)$ \\
AST increased & $58(11)$ & $16(3)$ & $26(5)$ & $5(<1)$ \\
\hline
\end{tabular}

* Adverse events of special interest were selected on the basis of the safety profile of phase 2 and phase 3 studies of abiraterone. ALT denotes alanine aminotransferase, and AST aspartate aminotransferase.

$\uparrow$ Cardiac disorders included ischemic heart disease, myocardial infarction, supraventricular tachyarrhythmia, ventricular tachyarrhythmia, cardiac failure, and possible arrhythmia-related investigations, signs, and symptoms. 
graphic progression-free survival (median time to event, 16.5 months vs. 8.3 months; hazard ratio, 0.53), as compared with placebo plus prednisone. Patients receiving abiraterone also had an extended time until the initiation of opiate analgesia, treatment with cytotoxic chemotherapy, or a decline in performance status, as well as delays in PSA progression, onset of pain, and decline in health-related quality of life. The proportion of men in the abiraterone-prednisone group with a PSA response and the time to PSA progression are consistent with outcomes reported in earlier phase 1 or 2 studies of abiraterone. ${ }^{20-22}$ In addition, a strong trend toward improved survival (hazard ratio, 0.75) was evident at the time at which $43 \%$ of the prespecified total number of events required for the final analysis had occurred. This consistent pattern of benefit resulted in the unanimous decision of the data and safety monitoring committee to recommend unblinding of the study and crossover of patients in the prednisone-alone group to abiraterone treatment.

Despite the various therapies available for men with metastatic castration-resistant prostate cancer, a need remains for effective nontoxic agents that can improve and maintain the quality and duration of life while preventing the morbidity associated with disease progression. ${ }^{25}$ Secondline hormonal manipulation with antiandrogens, diethylstilbestrol, and ketoconazole has long been used on the sole basis of symptom relief and PSA-level response data. ${ }^{8}$ This pattern of use has persisted despite the availability of two new agents with a survival benefit: docetaxel, the use of which is limited by toxic effects, and sipuleucel-T, the use of which is limited by a lack of demonstrable antitumor activity. The durable antitumor effect and safety profile of abiraterone confirms earlier experience that it can be used long term without concern for life-threatening toxic effects. ${ }^{21,22}$

Glucocorticoids have beneficial effects in patients with metastatic castration-resistant prostate cancer, and prednisone has been an active comparison agent in randomized trials for decades. ${ }^{4,7,19}$ Our data show that targeting persistent extragonadal androgen synthesis ${ }^{26}$ leads to benefits that exceed those with standard prednisone therapy used in current clinical trials. An additional notable finding is that the median overall survival of 27.2 months with prednisone alone is the longest survival prospectively observed in this patient population, possibly a consequence of antitumor activity of the prednisone control and the activity of subsequent effective therapies.

In addition to the marked improvement in radiographic progression-free survival, treatment with abiraterone was associated with a trend toward improved overall survival. Evidence of the magnitude of the survival benefit of abiraterone-prednisone, as compared with prednisone alone, was that treatment effects were consistently favorable across all prespecified patient subgroups, including older men and those with a decreased performance status, increased pain, and increased disease burden (Fig. 1D). The use of abiraterone after crossover among patients originally assigned to the prednisone-alone group may affect the ability to show statistical significance in subsequent analyses of overall survival. Despite the high disease burden and the proportion of patients with high-grade tumors (Gleason score, $\geq 8$ ) who were enrolled, the survival curves did not separate until after approximately 12 months. This finding can be ascribed to the use of an active prednisone control and the low rate of early death in asymptomatic or mildly symptomatic patients with metastatic castration-resistant cancer.

Early deaths related to cancer may occur in patients with a tumor phenotype against which androgen modulation may have little effect. Although we do not know the effectiveness of therapies (including abiraterone) that were used after termination of the study treatment, the prevalence of subsequent therapy was higher in the prednisone-alone group than in the abirateroneprednisone group (60\% and $44 \%$, respectively) (Table S5 in the Supplementary Appendix). The most common subsequent therapy in the two groups was docetaxel. Between-group disparities in subsequent therapies may be attributable to the greater number of patients in the abirateroneprednisone group who continued to receive the drug, as compared with the prednisone-alone group: 166 of 542 patients (31\%) in the abiraterone-prednisone group vs. 86 of 540 patients $(16 \%)$ in the prednisone-alone group.

The safety of abiraterone in this study was similar to that previously reported in men with metastatic castration-resistant prostate cancer and disease progression after docetaxel chemotherapy. ${ }^{19}$ No toxic effects unique to this patient population were identified (a finding that was consistent with previous studies), despite a longer 
duration of abiraterone-prednisone treatment. Liver-function abnormalities (typically seen in the first 3 months of therapy) and cardiac toxic effects were more common in the abirateronetreated patients than in the prednisone-alone group. Cardiac abnormalities tended to appear later. Discontinuation of therapy because of toxicity occurred in $10 \%$ of patients in the abiraterone-prednisone group and in $9 \%$ of patients in the prednisone-alone group.

In summary, the results show benefit from the use of abiraterone in patients with asymptomatic or mildly symptomatic metastatic castration-resistant prostate cancer who have not received previous chemotherapy. These findings include increased rates of radiographic progression-free survival and overall survival, as well as clinically meaningful secondary end points, such as delays in the use of opiates for pain and chemotherapy and patient-reported outcomes related to health-related quality of life.

Presented in part at the annual meeting of the American Society of Clinical Oncology, Chicago, June 1-5, 2012 (abstract LBA4518).

Supported by Ortho Biotech Oncology Research and Development, a unit of Cougar Biotechnology (now Janssen Research and Development).

Disclosure forms provided by the authors are available with the full text of this article at NEJM.org.

We thank the patients who volunteered to participate in this study and the study site staff who cared for them, and Namit Ghildyal, Ph.D., an employee of the study sponsor, and Ira Mills, Ph.D., of Parexel, for editorial assistance with an earlier draft of the manuscript.

\section{APPENDIX}

The authors' affiliations are as follows: the Helen Diller Family Comprehensive Cancer Center, University of California, San Francisco (C.J.R., E.J.S.); Massachusetts General Hospital Cancer Center (M.R.S.) and Dana-Farber Cancer Institute (M.-E.T.) - both in Boston; the Institute of Cancer Research and the Royal Marsden Hospital, Sutton, United Kingdom (J.S.B.); Janssen Research and Development (A.M., Y.P., T.K., T.G.) and David Geffen School of Medicine, University of California (A.P.) - both in Los Angeles; M.D. Anderson Cancer Center, Houston (C.J.L., E.E.); St. George Private Hospital, Kogarah (P.S.), Haematology and Oncology Clinics of Australia, Brisbane (P.M.), and St. John of God Hospital, Subiaco (S.N.) - all in Australia; Institut Gustave Roussy, University of Paris Sud, Villejuif, France (K.F.); Institut Català d'Oncologia de l'Hospitalet (J.M.P.) and Universitari Vall d'Hebron (J.C.) — both in Barcelona; Radboud University Medical Center, Nijmegen (P.F.A.M.), and VU University Medical Center, Amsterdam (W.R.G.) - both in the Netherlands; Memorial Sloan-Kettering Cancer Center, New York (E.B., H.I.S., D.E.R.); University of Montreal, Montreal (F.S.), Juravinski Cancer Centre Hamilton Health Services, Hamilton, ON (S.D.M.), and London Health Sciences Centre, London, ON (E.W.) - all in Canada; Hospital Network Antwerp (ZNA)-Middelheim, Antwerp (D.S.), and University Hospital Leuven, Leuven (H.V.P.) - both in Belgium; Urologikum Hamburg, Hamburg, Germany (H.S.); University of Colorado Cancer Center, Aurora (T.W.F.); Duke University Hospital Medical Center, Durham, NC (D.J.G.); University of Washington, Seattle (E.Y.Y., C.S.H.); and Department of Clinical Therapeutics, University of Athens Medical School, Alexandra Hospital, Athens (E.E.).

\section{REFERENCES}

1. Jemal A, Bray F, Center MM, Ferlay J, Ward E, Forman D. Global cancer statistics. CA Cancer J Clin 2011;61:69-90. [Erratum, CA Cancer J Clin 2011;61:134.]

2. Scher HI, Halabi S, Tannock I, et al. Design and end points of clinical trials for patients with progressive prostate cancer and castrate levels of testosterone: recommendations of the Prostate Cancer Clinical Trials Working Group. J Clin Oncol 2008;26:1148-59.

3. Crawford ED, Eisenberger MA, McLeod DG, et al. A controlled trial of leuprolide with and without flutamide in prostatic carcinoma. N Engl J Med 1989; 321:419-24. [Erratum, N Engl J Med 1989; 321:1420.]

4. Tannock IF, de Wit R, Berry WR, et al. Docetaxel plus prednisone or mitoxantrone plus prednisone for advanced prostate cancer. N Engl J Med 2004;351:150212.

5. Petrylak DP, Tangen CM, Hussain $\mathrm{MH}$, et al. Docetaxel and estramustine compared with mitoxantrone and prednisone for advanced refractory prostate cancer. N Engl J Med 2004;351:1513-20.

6. Saad F, Gleason DM, Murray R, et al. A randomized, placebo-controlled trial of zoledronic acid in patients with hormonerefractory metastatic prostate carcinoma. J Natl Cancer Inst 2002;94:1458-68.

7. Sternberg CN, Petrylak DP, Sartor O, et al. Multinational, double-blind, phase III study of prednisone and either satraplatin or placebo in patients with castrate-refractory prostate cancer progressing after prior chemotherapy: the SPARC trial. J Clin Oncol 2009;27:5431-8.

8. Small EJ, Vogelzang NJ. Second-line hormonal therapy for advanced prostate cancer: a shifting paradigm. J Clin Oncol 1997;15:382-8.

9. Engel-Nitz NM, Alemayehu B, Parry D, Nathan F. Differences in treatment patterns among patients with castrationresistant prostate cancer treated by oncologists versus urologists in a US managed care population. Cancer Manag Res 2011;3:233-45.

10. Harris V, Lloyd K, Forsey S, Rogers P, Roche M, Parker C. A population-based study of prostate cancer chemotherapy. Clin Oncol (R Coll Radiol) 2011;23:706-8. 11. Kantoff PW, Higano CS, Shore ND, et al. Sipuleucel-T immunotherapy for castration-resistant prostate cancer. N Engl J Med 2010;363:411-22.
12. Attard G, Belldegrun AS, de Bono JS. Selective blockade of androgenic steroid synthesis by novel lyase inhibitors as a therapeutic strategy for treating metastatic prostate cancer. BJU Int 2005;96: 1241-6.

13. Barrie SE, Haynes BP, Potter GA, et al. Biochemistry and pharmacokinetics of potent non-steroidal cytochrome P450 (17alpha) inhibitors. J Steroid Biochem Mol Biol 1997;60:347-51.

14. Jarman M, Barrie SE, Llera JM. The 16,17 -double bond is needed for irreversible inhibition of human cytochrome p45017alpha by abiraterone (17-(3-pyridyl) androsta-5, 16-dien-3beta-ol) and related steroidal inhibitors. J Med Chem 1998; 41:5375-81.

15. Potter GA, Barrie SE, Jarman M, Rowlands MG. Novel steroidal inhibitors of human cytochrome P45017 alpha (17 alpha-hydroxylase-C17,20-lyase): potential agents for the treatment of prostatic cancer. J Med Chem 1995;38:2463-71.

16. Molina A, Belldegrun A. Novel therapeutic strategies for castration resistant prostate cancer: inhibition of persistent androgen production and androgen receptor mediated signaling. J Urol 2011; 
185:787-94. [Erratum, J Urol 2011;186: 762.]

17. Holzbeierlein J, Lal P, LaTulippe E, et al. Gene expression analysis of human prostate carcinoma during hormonal therapy identifies androgen-responsive genes and mechanisms of therapy resistance. Am J Pathol 2004;164:217-27.

18. Montgomery RB, Mostaghel EA, Vessella $\mathrm{R}$, et al. Maintenance of intratumoral androgens in metastatic prostate cancer: a mechanism for castration-resistant tumor growth. Cancer Res 2008;68:444754.

19. de Bono JS, Logothetis CJ, Molina A, et al. Abiraterone and increased survival in metastatic prostate cancer. N Engl J Med 2011;364:1995-2005.
20. Attard G, Reid AH, A'Hern R, et al Selective inhibition of CYP17 with abiraterone acetate is highly active in the treatment of castration-resistant prostate cancer. J Clin Oncol 2009;27:3742-8.

21. Ryan CJ, Smith MR, Fong L, et al Phase I clinical trial of the CYP17 inhibitor abiraterone acetate demonstrating clinical activity in patients with castration-resistant prostate cancer who received prior ketoconazole therapy. J Clin Oncol 2010;28:1481-8.

22. Ryan CJ, Shah S, Efstathiou E, et al. Phase II study of abiraterone acetate in chemotherapy-naive metastatic castration-resistant prostate cancer displaying bone flare discordant with serologic response. Clin Cancer Res 2011;17:4854-61.
23. Hochberg Y. A sharper Bonferroni procedure for multiple tests of significance. Biometrika 1988;75:800-2.

24. Molenberghs G, Burzykowski T, Alonso A, Buyse M. A perspective on surrogate endpoints in controlled clinical trials. Stat Methods Med Res 2004;13:177206.

25. Garcia JA, Rini BI. Castration-resistant prostate cancer: many treatments, many options, many challenges ahead. Cancer 2012;118:2583-93.

26. Efstathiou E, Titus M, Tsavachidou D, et al. Effects of abiraterone acetate on androgen signaling in castrate-resistant prostate cancer in bone. J Clin Oncol 2012;30:637-43.

Copyright (c) 2012 Massachusetts Medical Society.

\section{ICMJE SEEKING TWO NEW MEMBER JOURNALS}

The International Committee of Medical Journal Editors (ICMJE) is seeking two new member journals to be represented by their editors-in-chief. Information about the ICMJE is available at www.icmje.org. Candidate journals should meet the following criteria:

- be a peer-reviewed general medical journal that publishes original research involving humans

- have a governance structure that ensures editorial independence

- have an editor with experience in the position who expects to continue in the position for at least another 3 years

- be financially able to support the editor's participation in ICMJE activities

In considering candidates, the ICMJE may seek to improve the balance of geographic areas and publishing models among its membership.

To apply, editors-in-chief of interested journals should submit the following materials to the ICMJE (at icmje@acponline.org):

- brief curriculum vitae

- cover letter describing the journal, including but not necessarily limited to details of the journal's history, sponsor or publisher, governance structure, publishing model (e.g., subscription, author-pays open access), target audience, print circulation and online traffic, number of manuscript submissions per year, processes used to select material for publication, acceptance rate, databases where indexed, website address, and guidelines for authors

- statement on how the journal might benefit from ICMJE membership and how the ICMJE might benefit from the journal's membership (should not exceed 1000 words)

The deadline for applications is January 31, 2013. 